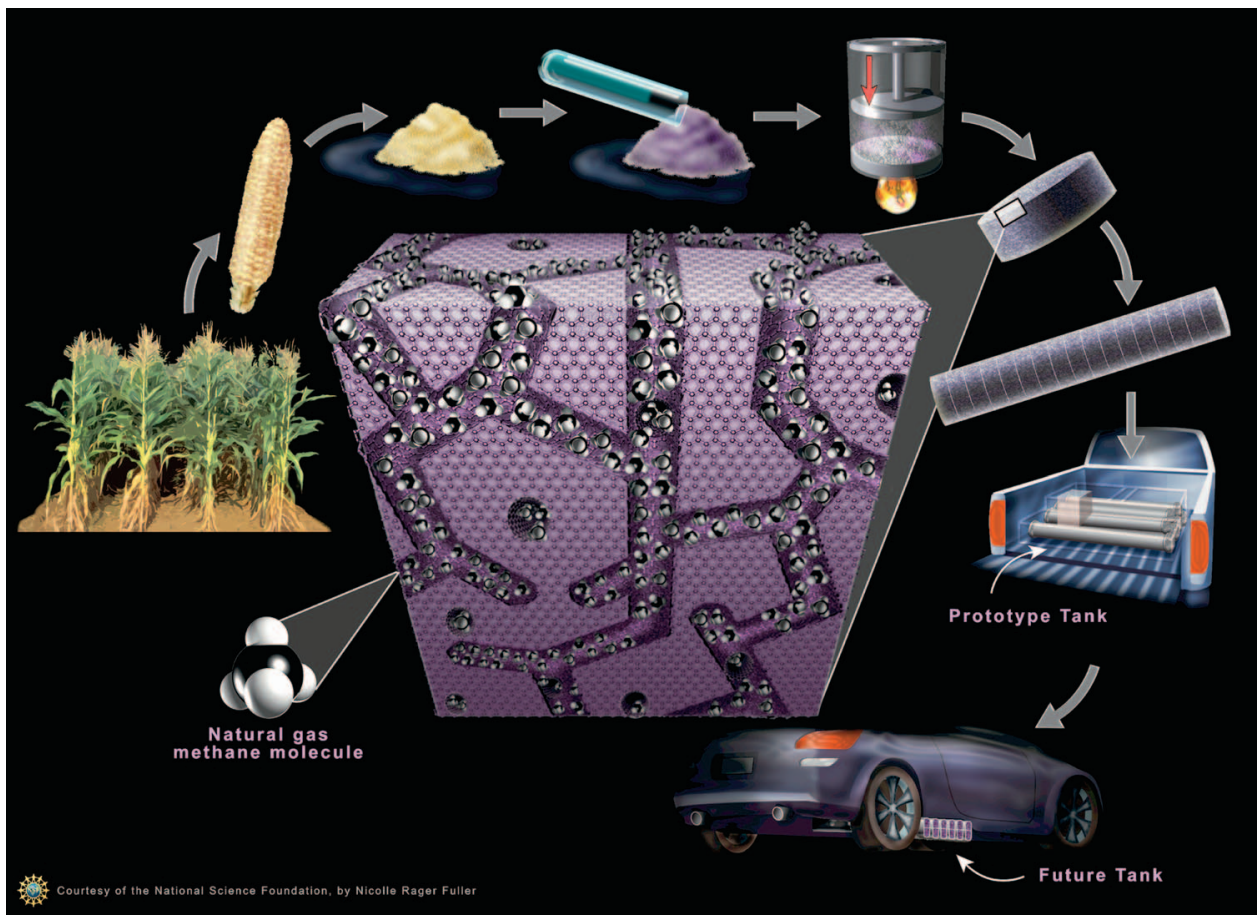

FIG. 1. (Color)

\section{Complex pore spaces create record-breaking methane storage system for natural-gas vehicles}

P. Pfeifer, L. Aston, M. Banks, S. Barker, J. Burress,

S. Carter, J. Coleman, S. Crockett, C. Faulhaber, J. Flavin, M. Gordon, L. Hardcastle, Z. Kallenborn, M. Kemiki, C. Lapilli, J. Pobst, R. Schott, P. Shah, S. Spellerberg, G. Suppes, D. Taylor, A. Tekeei, C. Wexler, and M. Wood

University of Missouri, Columbia, Missouri 65211, USA

P. Buckley, T. Breier, J. Downing, S. Eastman,

P. Freeze, S. Graham, S. Grinter, A. Howard,

J. Martinez, D. Radke, and T. Vassalli

Midwest Research Institute, Kansas City, Missouri 64110, USA

J. llavsky

Argonne National Laboratory, Argonne, Illinois 60439, USA

(Received 27 August 2007; published online 27 December 2007)

[DOI: $10.1063 / 1.2786007$ ]

It has been proposed that nearly space-filling networks of nanopores in biocarbon may provide a "sponge" for lowpressure, high-capacity storage of methane $\left(\mathrm{CH}_{4}\right)$ for advanced transportation. ${ }^{1}$ Such pores, a few molecular diameters wide, adsorb $\mathrm{CH}_{4}$ by strong van der Waals forces as a high-density fluid at low pressure and room temperature (supercritical adsorption). The dense fluid arises because, in narrow pores, the tails of the substrate potential from opposite walls overlap and create a deep potential well. In the absence of nanopores, $\mathrm{CH}_{4}$ would just be a low-density gas. Maximum density of $\mathrm{CH}_{4}$ is predicted in pores of width $1.1 \mathrm{~nm}{ }^{2}$

In a program launched in 2004-Alliance for Collaborative Research in Alternative Fuel Technology (ALLCRAFT), a partnership of the University of Missouri and the Midwest Research Institute ${ }^{3}$ - we have developed nanoporous carbon, made from waste corncob in a multistep process, which stores $\mathrm{CH}_{4}$ at an unprecedented capacity of
$118 \mathrm{~g} \mathrm{CH}_{4} /$ liter carbon, or 180 times its own volume (DOE target), at 35 bar and ambient temperature. This provides the technology to replace bulky cylindrical compressed natural gas tanks (250 bar) in current natural-gas vehicles by a flat, light-weight tank with storage as adsorbed natural gas, under the floor of a car, in next-generation clean vehicles. Natural gas is an attractive motor fuel because it gives near zero emissions, is largely domestic (85\% of the U.S. consumption is produced in the U.S., $12 \%$ in Canada), can be produced in significant amounts from renewable sources (biomethane), and costs 30\%-60\% less than gasoline or diesel at the pump per energy equivalent.

We have manufactured over 300 disk-shaped carbon briquettes, loaded them in a prototype tank and fuel delivery system, and installed the system on a natural-gas vehicle. The tank was showcased in Kansas City in February 2007, ${ }^{4}$ and is currently undergoing an extensive road test.

Our best carbons have pore widths between 0.5 and $1.2 \mathrm{~nm}$, and only few larger pores. From ultrasmall-angle $\mathrm{x}$-ray scattering, we infer that the pores can be modeled as cylinders of average width $0.8 \mathrm{~nm}$ and length $1.2 \mathrm{~nm}$, but their complex spatial organization at large scales remains to be worked out.

This work has been supported by NSF (PFI-0438469), DOE (DE-AC02-06CH11357), DED (P200A040038), University of Missouri, Midwest Research Institute, and Kansas City Office of Environmental Quality (loan of test vehicle). We thank Nicolle Rager, NSF, for the superb graphic.

\footnotetext{
${ }^{1}$ P. Pfeifer, F. Ehrburger-Dolle, T. P. Rieker, M. T. González, W. P. Hoffman, M. Molina-Sabio, F. Rodríguez-Reinoso, P. W. Schmidt, and D. J. Voss, Phys. Rev. Lett. 88, 115502 (2002).

${ }^{2}$ S. K. Bhatia and A. L. Myers, Langmuir 22, 1688 (2006). ${ }^{3}$ http://all-craft.missouri.edu

${ }^{4}$ http://www.nsf.gov/news/news_summ.jsp?cntn_id=108390\&org $=\mathrm{NSF} \&$ from $=$ news
} 